\title{
Minor difference in postprandial responses of men between starch and sugar when replacing fat in a normal meal
}

\author{
BY J. M. M. VAN AMELSVOORT, P. VAN STRATUM, J. F. KRAAL, \\ R. N. LUSSENBURG AND G. P. DUBBELMAN \\ Unilever Research Laboratorium Vlaardingen, PO Box 114, 3130 AC Vlaardingen, The Netherlands
}

(Received 21 December 1988 - Accepted I August 1989)

\begin{abstract}
Healthy male volunteers consumed hot lunches consisting of cooked white rice, fried chicken fillet, raisins, bigarreaus (sweet cherries) and curry sauce with carbohydrate: fat ratios of either 0.77 or 2.04 , and polysaccharide: (mono + di)saccharide ratios ( $P: M D)$ varying between 5.3 and 0.95 . Before and at various time intervals after the start of the meal, blood samples were analysed for glucose, insulin, triacylglycerol (TG), free glycerol (FG), free fatty acids (FFA) and cholesterol. Elevated postprandial glucose and insulin peaks were induced by the meals containing a larger amount of carbohydrate. The type of carbohydrate in the meal appeared to have little or no effect on the peak maximum. A small second glucose peak was seen at $2 \mathrm{~h}$ after the meals with $\mathrm{P}: \mathrm{MD}>3 \cdot 1$. The TG concentration in the blood showed a similar and rapid rise. After the meal containing the largest amount of simple sugars, the TG curve levelled off $1 \mathrm{~h}$ after the start of the meal and then remained at a nearly constant level $(1 \cdot 5$ mM). In contrast, a larger amount of complex carbohydrates induced a TG concentration which rapidly rose to a maximum of $1.75 \mathrm{~mm}$, and subsequently decreased slowly to somewhat below that of the simple sugar-rich meal at $4 \mathrm{~h}$. The postprandial curves after the fat-rich meals showed a continuous rise of TG up to a maximum of about $2 \mathrm{~mm}$ at $2 \mathrm{~h}$, and a subsequent slow decrease. FG and FFA all showed a rapid drop immediately after the start of the consumption of the meals, followed by a rebound at $1 \mathrm{~h}$. The postprandial curves of total cholesterol, as well as the areas below the curve of both total cholesterol and free, unesterified cholesterol were lower after the carbohydrate-rich meals than after the fat-rich meals. This is attributed to the larger amount of cholesterol in the fat-rich meals.
\end{abstract}

Meal eating: Postprandial responses: Carbohydrate to fat ratio

Dietary habits may affect health, both by inducing gradual changes in the long term (chronic effects) and by changes occurring after each meal (postprandial effects): the fluctuations that are induced by meals in blood glucose, insulin and lipids are increasingly being accepted as relevant to the development of various diseases, e.g. atherosclerosis, obesity, maturity-onset diabetes.

Recently, health councils in various countries of the Western world have advised reducing the consumption of dietary fat to about $30 \%$ of energy intake, and to increase the intake of complex carbohydrates and dietary fibre. In a previous study, a significant positive relation was found between the amount of carbohydrate in meals and the area under the postprandial curves of glucose and insulin in the blood (van Amelsvoort et al. 1989). Since in the long run elevated mean insulin levels in the blood may lead to an insensitivity towards insulin, i.e. maturity-onset diabetes, this would suggest a potential risk of reducing the amount of fat in the diet in exchange for carbohydrate. Moreover, insulin may play a part in the development of atherosclerosis (Stout, 1985; Flodin, 1986). On the other hand, there was a systematic inverse relationship between the carbohydrate content of the meals and the peak area below the postprandial triacylglycerol curve (van Amelsvoort et al. 1989). A postprandial hyperlipidaemia is also regarded as a risk factor to human health (Zilversmit, 1979, 1984). Hence the carbohydrate:fat ratio most optimal for human health remains uncertain. 
In our previous study (van Amelsvoort et al. 1989) the polysaccharides:(mono+ di)saccharides ratio (P:MD) was kept constant at $2: 1$. Thus both saccharides were increased upon increasing the carbohydrate:fat ratio in the test meals. Since the type of carbohydrate, as well as the physical characteristics of the medium in which the carbohydrate is incorporated, can affect the postprandial glucose and insulin responses (Jenkins et al. 1983, 1984a, b, 1986; Torsdottir et al. 1984; Heraud, 1985; Lee et al. 1985; Crapo, 1986; Thorburn et al. 1987), the positive relation between carbohydrate:fat ratio and area below the glucose and insulin curves (van Amelsvoort et al. 1989) could very well be due mainly to a single component, or a particular group of components, in the carbohydrate fraction. Therefore, we have now studied the postprandial effects of increasing the carbohydrate:fat ratio in the meal by replacing fat with either polysaccharides or (mono + di)saccharides.

\section{METHODS}

\section{Volunteers}

The characteristics of the volunteers participating in the experiment should obey a number of minimal requirements: (1) they should participate freely and voluntarily and without expectation of any financial reward, (2) they should be as far as possible representative of people living in Western society, (3) they should be able to continue their normal daily activities during the experiment, and they should have a physiological 'constancy' during the experiment ( $4-5$ weeks).

The volunteers were recruited from the male staff of Unilever Research Laboratorium Vlaardingen. They were asked to give their written consent to participate in the study, and were checked for general health by an independent physician. Only volunteers who were considered to be healthy and who were not at elevated risk in view of the composition of the test meals and the blood sampling procedure were selected to participate. The average food intake of the volunteers was assessed by a dietician using the dietary history procedure (Marr, 1971). The nutrients consumed in the course of an average day and during an average hot meal were calculated using a standard Dutch Food Composition Table (Commissie UCV, 1984). In order to be able to extrapolate the findings of the study to dayto-day practice as much as possible, the volunteers who were to participate in the study were asked to keep to their normal, habitual daily activity pattern. After recruitment, thirty male volunteers passed the medical examination and completed the study. Their mean height, body-weight and age were 1.83 (range 1.69-2.01) m, 80 (range 62-110) $\mathrm{kg}$ and 38 (range 22-59) years respectively. The body mass index (weight/height ${ }^{2}$ ) varied between $19 \cdot 1$ (lean) and 26.6 (mildly obese) with one single exception of 31.5 (obese). The mean value (23.9) may be regarded as indicative of a normal, non-obese population.

\section{Test meals}

In principle, the hot test meals had to be of a common composition and appearance. Pilot studies led to the composition of single-dish test meals consisting of a mixture of cooked white rice, fried chicken fillet cut into approximately $20 \mathrm{~mm}$ cubes, raisins, sliced bigarreaus (sweet cherries) and curry sauce. To improve digestibility, half the raisins (containing the major part of the (mono + di)saccharides) were ground before use. Four different meals (Table 1) were studied, with dietary fat levels of $48 \%$ of energy (cn $\%$; meals HF/LMD and HF/LP) or 28 en $\%$ (meals LF/HP and LF/HMD). Starting with the meal containing a high amount of fat (meal HF/LMD), fat was reduced by exchanging it for either polysaccharides (meal LF/HP) or (mono+di)saccharides (meal LF/HMD). Like meal $\mathrm{HF} / \mathrm{LMD}$, meal HF/LP contained a high amount of fat, but the P: MD ratio was similar 
Table 1. Composition of the test meals*

\begin{tabular}{|c|c|c|c|c|c|c|c|c|}
\hline \multirow{2}{*}{$\begin{array}{l}\text { Meal } \\
\text { code }\end{array}$} & \multirow{2}{*}{$\begin{array}{c}\text { Fat } \\
(\mathrm{en} \%)\end{array}$} & \multicolumn{2}{|c|}{ Carbohydrate (en \%) } & \multirow{2}{*}{$\begin{array}{l}\mathrm{P}: \mathrm{MD} \\
\text { ratio }\end{array}$} & \multirow{2}{*}{$\begin{array}{c}\text { Carbohydrate: } \\
\text { fat ratio }\end{array}$} & \multirow{2}{*}{$\begin{array}{l}\text { Protein } \\
(\text { en } \%)\end{array}$} & \multirow{2}{*}{$\begin{array}{l}\text { Cholesterol } \\
(\mathrm{mg} / \mathrm{MJ})\end{array}$} & \multirow{2}{*}{$\begin{array}{c}\text { Dietary } \\
\text { fibre } \\
(\mathrm{g} / \mathrm{MJ})\end{array}$} \\
\hline & & $\mathbf{P}$ & MD & & & & & \\
\hline $\mathrm{LF} / \mathrm{HP}$ & 28 & 48 & 9 & $5 \cdot 3$ & $2 \cdot 04$ & 15 & 11 & 1.9 \\
\hline $\mathrm{HF} / \mathrm{LMD}$ & 48 & 28 & 9 & $3 \cdot 1$ & 0.77 & 15 & 20 & $1 \cdot 3$ \\
\hline LF/HMD & 28 & 28 & 29 & 0.97 & $2 \cdot 04$ & 15 & 13 & $2 \cdot 3$ \\
\hline $\mathrm{HF} / \mathrm{LP}$ & 48 & 18 & 19 & $0 \cdot 95$ & $0 \cdot 77$ & 15 & 22 & 1.5 \\
\hline
\end{tabular}

en $\%, \%$ of energy; $P$, polysaccharides; MD, mono- and disaccharides; LF, low fat; HF, high fat; LMD, low mono- and disaccharides; HMD, high mono- and disaccharides; LP, low polysaccharides; HP, high polysaccharides.

* The ratio of saturated, mono- and polyunsaturated fatty acids was kept at $1: 1: 1$.

to that in meal LF/HMD. In this way the postprandial effects induced by meals LF/HMD or $\mathrm{HF} / \mathrm{LP}$ could be compared with those obtained in a previous meal-eating experiment in which we studied the effects of a variable carbohydrate: fat ratio in the meal at a constant P:MD ratio (van Amelsvoort et al. 1989).

Since the protein content of the meals was kept constant at approximately 15 en $\%$, the carbohydrate: fat ratios (on the basis of energy content) were 2.04 or 0.77 (Table 1). The dietary fat contained equal proportions of polyunsaturated fatty acids, mono-unsaturated fatty acids and saturated fatty acids. The P:MD ratios were $5 \cdot 3$ (meal LF/HP), $3 \cdot 1$ (meal HF/LMD), 0.97 (meal LF/HMD) and 0.95 (meal HF/LP).

Blood samples had to be collected while causing minimal disturbance of the normal activities of each individual. Since free-living human beings show large differences in their health indices, habitual physical activities and nutrient intake, one may expect a large variation in the postprandial responses. Therefore, each person acted as his own control by consuming all four test meals at intervals of at least 1 week on either Tuesday, Wednesday, Thursday or Friday. As there were four different test meals, these could be offered to the volunteers in twenty-four different sequences. As we had thirty volunteers, all twenty-four possible meal sequences have been used, and six sequences twice. The order in which a specific volunteer received the meals was determined by randomization, with the restriction that on each day of the experiment a maximum of eight volunteers took part, two for each type of test meal. This was realized by constructing a 4-week experimental design. Volunteers who were not able to participate on all the $4 \mathrm{~d}$ dictated by the experimental design were invited to consume the meal they had 'missed' in the fifth week on either Wednesday or Thursday.

\section{Consumption}

The volunteers were asked to keep a more or less similar consumption pattern, and to avoid excessive intakes of alcohol and snacks during the $2 \mathrm{~d}$ preceding the day on which a test meal was to be consumed. On the test day they consumed their habitual breakfast, and stopped drinking sugar-containing beverages and coffee at $09 \cdot 30$ hours. The test meals were served to the eight volunteers between 12.30 and 13.00 hours at 4 -min intervals. They were allowed $30 \mathrm{~min}$ to eat the meal.

The size of the volunteer's test meal was individually adjusted as follows: in the week preceding the experiment, the volunteers consumed ad lib. a meal which was composed of equal proportions of all four meal types (Table 1). Due to the high palatability of the resulting meal, however, the volunteers consumed unrealistically large amounts of it. In 
Table 2. Mean daily energy intakes and carbohydrate: fat ratios in the dinner, and in the total consumption calculated from dietary histories of the volunteers

(Mean values with their standard errors for thirty volunteers)

\begin{tabular}{|c|c|c|c|c|c|c|c|c|c|}
\hline & \multicolumn{2}{|c|}{ Energy (MJ) } & \multicolumn{2}{|c|}{$\begin{array}{l}\text { Percentage } \\
\text { of daily } \\
\text { energy intake }\end{array}$} & \multirow{2}{*}{\multicolumn{4}{|c|}{ Distribution of energy $(\%)$}} & \multirow{3}{*}{$\begin{array}{c}\text { Carbohydrate } \\
\text { fat ratio }\end{array}$} \\
\hline & \multirow[b]{2}{*}{ Habitual } & \multirow{2}{*}{$\begin{array}{l}\text { Test } \\
\text { meal }\end{array}$} & \multirow[b]{2}{*}{ Habitual } & \multirow{2}{*}{$\begin{array}{l}\text { Test } \\
\text { meal }\end{array}$} & & & & & \\
\hline & & & & & Protein & Fat & Carbohydrate & Alcohol & \\
\hline \multicolumn{10}{|c|}{ Total consumption } \\
\hline Mean & $12 \cdot 1$ & - & - & - & $13 \cdot 5$ & $39 \cdot 9$ & $41 \cdot 1$ & $5 \cdot 5$ & $1 \cdot 04$ \\
\hline SEM & $0 \cdot 46$ & $-\cdots$ & - & - & $0 \cdot 29$ & 0.65 & 0.72 & 0.73 & $0 \cdot 030$ \\
\hline \multicolumn{10}{|l|}{ Range: } \\
\hline Minimum & $6 \cdot 32$ & - & - & - & $10 \cdot 5$ & $32 \cdot 2$ & $33 \cdot 2$ & 0.0 & 0.75 \\
\hline Maximum & $17 \cdot 97$ & $\cdots$ & - & - & $16 \cdot 8$ & $45 \cdot 4$ & $50 \cdot 5$ & 13.9 & $1 \cdot 48$ \\
\hline \multicolumn{10}{|l|}{ Dinner } \\
\hline Mean & $4 \cdot 2$ & $3 \cdot 9$ & $34 \cdot 7$ & $32 \cdot 6$ & $17 \cdot 7$ & $44 \cdot 5$ & $35 \cdot 1$ & $2 \cdot 7$ & $0 \cdot 82$ \\
\hline SEM & $0 \cdot 22$ & $0 \cdot 21$ & $1 \cdot 19$ & $1 \cdot 51$ & 0.52 & $1 \cdot 23$ & 0.95 & 0.73 & $0 \cdot 044$ \\
\hline \multicolumn{10}{|l|}{ Range: } \\
\hline Minimum & $2 \cdot 15$ & $2 \cdot 1$ & 22 & 16 & $13 \cdot 0$ & $30 \cdot 5$ & $26 \cdot 6$ & $0 \cdot 0$ & 0.47 \\
\hline Maximum & 6.89 & $7 \cdot 2$ & 56 & 54 & $25 \cdot 7$ & $59 \cdot 2$ & $47 \cdot 3$ & $15 \cdot 8$ & 1.35 \\
\hline
\end{tabular}

order to prevent problems in the subsequent experiment, especially with the large-volume low-fat meal types, the actual meal sizes were adjusted downwards using the dietary histories of the volunteers and a factor to correct for the increase in size of the highcarbohydrate meals. The average size of the meal served in the experiment is given in Table 2. After the meal the volunteers were allowed to drink only beverages containing little or no sugar.

\section{Blood sampling, analysis and data processing}

Blood samples were taken in a seated position shortly before (about $10 \mathrm{~min}$ ), and at $0.5,1$, $1 \cdot 5,2$ and $4 \mathrm{~h}$ after the start of the meal. Glucose, insulin, total and free glycerol, free fatty acids and total and free cholesterol were determined in serum or plasma as described previously (van Amelsvoort et al. 1989). The choice of the variables and the data screening have been described in detail (van Amelsvoort et al. 1989). The statistical evaluation by analysis of (co)variance took into account the intrinsic individual levels as well as the initial values before the start of the meals. The treatment effects have been determined using the Student-Newman-Keuls multiple-range test. No error bars are given in the figures since these are related to the inter-individual variations and would have given a wrong impression of the significance of the results.

\section{Ethical considerations}

The protocol of the experiment was scrutinized for its ethical consequences, and approved by an external committee composed of three independent experts in the field.

\section{RESULTS}

The dietary history of the volunteers (Table 2 ) shows that the mean daily energy intake varied between 6.32 and $17.97 \mathrm{MJ}$ and averaged about $12.1 \mathrm{MJ}$. The mean intakes of energy as protein and carbohydrate were 13.5 and $41 \cdot 1$ en $\%$ respectively. The intake of fat was 
Table 3. Energy contribution (\%) of mono- and disaccharides $(M D)$, polysaccharides $(P)$ and saturated fat, ratio of $P: M D$, ratio of polyunsaturated:saturated fatty acids $(P: S)$ and content of dietary fibre $(g)$ in the total daily consumption and in the dinner (as part of the usual dietary intake) of volunteers

(Mean values with their standard errors for thirty volunteers)

\begin{tabular}{|c|c|c|c|c|c|c|}
\hline & \multicolumn{3}{|c|}{ Energy $(\%)$} & \multirow[b]{2}{*}{$\mathrm{P}: \mathrm{MD}$} & \multirow{2}{*}{\multicolumn{2}{|c|}{$\begin{array}{c}\text { Dietary } \\
\text { fibre } \\
\text { (g) }\end{array}$}} \\
\hline & MD & $\mathbf{P}$ & Saturated fat & & & \\
\hline \multicolumn{7}{|c|}{ Total consumption } \\
\hline Mean & $19 \cdot 0$ & $21 \cdot 8$ & $16 \cdot 1$ & $1 \cdot 24$ & $0 \cdot 56$ & $32 \cdot 9$ \\
\hline SEM & 0.69 & 0.68 & 0.34 & $0 \cdot 105$ & 0.037 & $1 \cdot 41$ \\
\hline \multicolumn{7}{|l|}{ Range: } \\
\hline Minimum & $8 \cdot 3$ & $15 \cdot 3$ & $12 \cdot 0$ & 0.69 & $0-22$ & $21 \cdot 7$ \\
\hline Maximum & $26 \cdot 2$ & $31 \cdot 5$ & $20 \cdot 6$ & $3 \cdot 80$ & 0.94 & $54 \cdot 2$ \\
\hline \multicolumn{7}{|l|}{ Dinner } \\
\hline Mean & $11 \cdot 7$ & $23 \cdot 6$ & $16 \cdot 3$ & $2 \cdot 26$ & 0.71 & $14 \cdot 3$ \\
\hline SEM & 0.59 & 0.91 & 0.60 & $0-21$ & $0 \cdot 062$ & $0 \cdot 83$ \\
\hline \multicolumn{7}{|l|}{ Range: } \\
\hline Minimum & $5 \cdot 1$ & $16 \cdot 5$ & $9 \cdot 3$ & $1 \cdot 10$ & 0.21 & 8.9 \\
\hline Maximum & $16 \cdot 7$ & $34 \cdot 6$ & $22 \cdot 7$ & $6 \cdot 78$ & $1 \cdot 41$ & $25 \cdot 4$ \\
\hline
\end{tabular}

about 39.9 en $\%$, which is very similar to the present fat intake in Western society. The mean daily intake of alcohol was $5.5 \mathrm{en} \%$, but in one case amounted to $13.9 \mathrm{en} \%$. The carbohydrate: fat ratio in the diet was about 1.04 , which is intermediate between test meals $\mathrm{HF} / \mathrm{LMD}$ or HF/LP and LF/HP or LF/HMD (see Table 1).

The mean energy intake in the dinner of the volunteers was about $4 \cdot 2 \mathrm{MJ}$, which represents $35 \%$ of the total daily energy intake (Table 2 ). However, this value varied between 22 and $56 \%$. The average size of the individually adjusted test meals is also shown in Table 2.

The percentages of the intake of polysaccharides in the total daily consumption and in the dinner were very similar $(21.8$ and $23.6 \%$ respectively, Table 3$)$. In contrast, the (mono + di)saccharides consumption was higher in the total consumption than in the dinner (19.0 and 11.7 respectively). This resulted in a higher $P$ :MD ratio in the dinner (2.26) compared with that in the total consumption (1.24). In addition, the percentages of saturated fat in the total consumption and in the dinner were very similar (16.1 and $16.3 \%$ respectively). However, the polyunsaturated: saturated fatty acid ratio was significantly lower in the total consumption compared with that in the dinner $(0.56$ and 0.71 respectively). The amounts of dietary fibre in total and in the dinner only were $32.9 \mathrm{~g}$ and $14.3 \mathrm{~g}$ respectively, which indicates that an appreciable amount of this nutrient is consumed at dinner.

The postprandial glucose curves after the four meals are shown in Fig. 1. The highest mean value in the postprandial curves was observed 30 min after the start of the meal in all cases. The glucose concentration at the next measuring point, i.e. $60 \mathrm{~min}$, was always considerably lower. The frequency of blood sampling did not allow a precise location of the glucose peak. The highest observed individual values of the glucose concentrations may, however, be assumed to be representative of the average maximum blood glucose value after each meal type, and can, therefore, be used in comparing the effects of the various meals on blood glucose (van Amelsvoort et al. 1989).

A higher postprandial glucose peak $(P<0.01)$ was observed after meals LF/HP or 


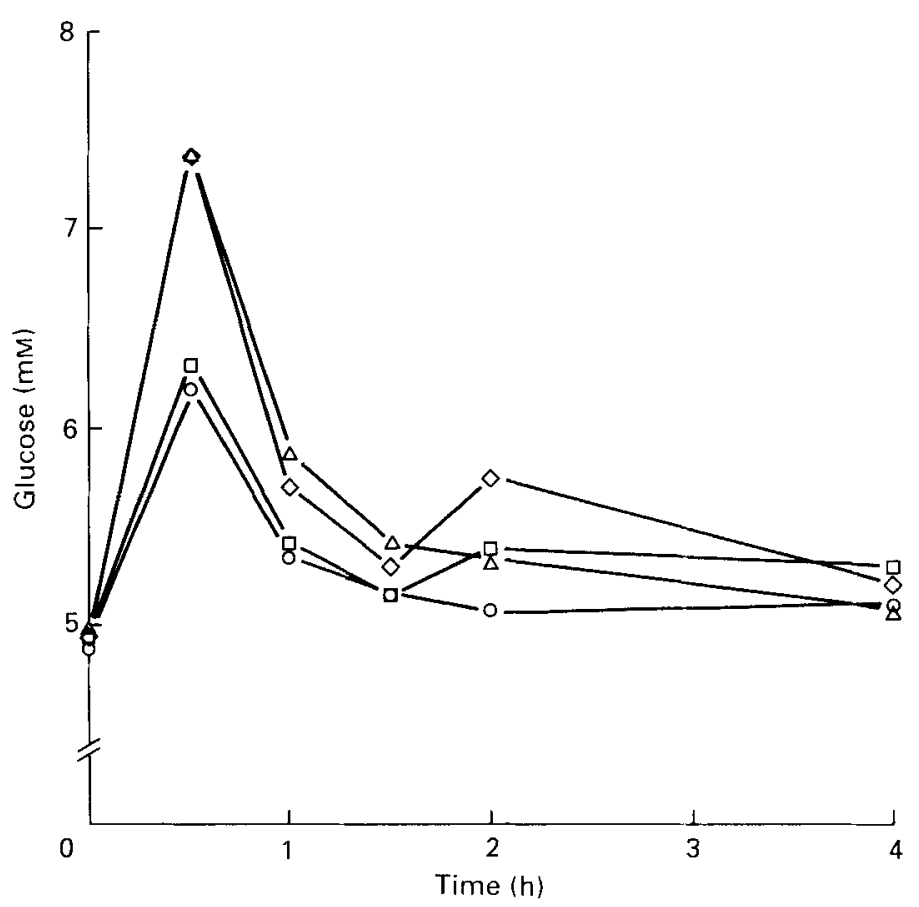

Fig. 1. Mean concentrations of glucose in blood plasma from male volunteers $(n 30)$ at various time-points after the start of the consumption of meals containing either $57 \%$ of energy $(\mathrm{en} \%$ LF $/ \mathrm{HP}, \mathrm{LF} / \mathrm{HMD})$ or 37 en $\%$ (HF/LMD, HF/LP) as carbohydrate, and a polysaccharide: mono + disaccharide ratio of $5 \cdot 3$ (LF/HP, $\diamond), 3 \cdot 1$ (HF/LMD, $\square$ ), 0.97 (LF/HMD, $\triangle$ ) or 0.95 (HF/LP, O). For details of diets, see Table 1.

LF/HMD which both contained 57 en $\%$ carbohydrate than after meals HF/LMD or HF/LP which contained only 37 en $\%$ carbohydrate (Table 1). This is in line with our previous finding of a linear relationship between the carbohydrate content of the meal and the postprandial glucose peak (van Amelsvoort et al. 1989). The type of carbohydrate in the meal appeared to have no effect on the peak maximum. A second glucose peak was seen $2 \mathrm{~h}$ after the start of the consumption of meal LF/HP $(P<0.05)$ and also, but somewhat less pronounced, after meal HF/LMD $(P=0 \cdot 10)$ but not after meals LF/HMD or HF/LP.

An alternative way of expressing the postprandial glucose response is to use the so-called glycaemic index (Thorburn et al. 1986; Wolever \& Jenkins, 1986). This index is calculated by expressing the peak area of the blood glucose curve after the consumption of a given food component as the percentage of the peak area obtained after the consumption of a similar limited amount (e.g. $50 \mathrm{~g}$ ) of a standard food, e.g. white bread. The food item to be analysed is consumed in the morning after an overnight fast. However, since in our experiments healthy individuals were studied at noon under non-fasting conditions, we previously (van Amelsvoort et al. 1989) calculated the postprandial response as the area below the curve during the whole analytical period i.e. $6 \mathrm{~h}$ (or $4 \mathrm{~h}$ in the present experiment). The mean areas below the curve thus obtained are given in Tables 4 and 5 . Larger areas $(P<0 \cdot 10)$ were obtained after the carbohydrate-rich meals $\mathrm{LF} / \mathrm{HP}$ or LF/HMD than after the fat-rich meals HF/LMD or HF/LP.

The postprandial curves of insulin in the sera are shown in Fig. 2. The starting values before the meals did not differ systematically, indicating that the volunteers had kept a 
Table 4. Total areas below the curve of the various postprandial variables (mM.h) of volunteers consuming test meals varying in carbohydrate:fat ratios and polysaccharide: mono- and disaccharides ratios (meals $L F / H P, H F / L M D, L F / H M D$ and $H F / L P$ )*

(Mean values with their standard errors for thirty volunteers)

\begin{tabular}{|c|c|c|c|c|c|c|c|c|}
\hline \multirow{2}{*}{$\begin{array}{l}\text { Meal type ... } \\
\text { Variable }\end{array}$} & \multicolumn{2}{|c|}{$\mathrm{LF} / \mathrm{HP}$} & \multicolumn{2}{|c|}{$\mathrm{HF} / \mathrm{LMD}$} & \multicolumn{2}{|c|}{ LF/HMD } & \multicolumn{2}{|c|}{$\mathrm{HF} / \mathrm{LP}$} \\
\hline & Mean & $\mathrm{SE}$ & Mean & $\mathrm{SE}$ & Mean & $\mathrm{SE}$ & Mean & $\mathrm{SE}$ \\
\hline Glucose & $22 \cdot 8$ & 0.36 & $21 \cdot 7$ & 0.34 & $22 \cdot 4$ & 0.34 & $21 \cdot 0$ & 028 \\
\hline Insulin (mU.h/l) & 148 & $10 \cdot 8$ & 115 & $8 \cdot 0$ & 137 & $9 \cdot 6$ & 106 & $4 \cdot 8$ \\
\hline Total glycerol & 6.48 & $0 \cdot 396$ & 7.04 & 0.416 & $5 \cdot 92$ & 0.400 & $7 \cdot 20$ & 0.428 \\
\hline Free glycerol & $0 \cdot 263$ & 0.0104 & 0.286 & 0.0096 & 0.256 & 0.0092 & 0.288 & 0.012 \\
\hline FFA & $1 \cdot 29$ & 0.048 & 1.77 & 0.072 & $1 \cdot 26$ & 0.056 & $1 \cdot 64$ & 0.076 \\
\hline Total cholesterol & $22 \cdot 8$ & 0.58 & $23 \cdot 4$ & 0.62 & $22 \cdot 9$ & 0.64 & $23 \cdot 1$ & 0.71 \\
\hline Total cholesterol, Adj† & $22 \cdot 73$ & 0.086 & $23 \cdot 06$ & 0.098 & $23 \cdot 03$ & 0092 & $23 \cdot 33$ & 0.096 \\
\hline Free cholesterol & $6 \cdot 19$ & $0 \cdot 152$ & 6.42 & $0 \cdot 196$ & $6 \cdot 24$ & $0 \cdot 184$ & $6 \cdot 30$ & $0 \cdot 196$ \\
\hline Free cholesterol, Adj† & $6 \cdot 14$ & $0-071$ & 6.33 & 0.065 & $6 \cdot 20$ & 0.066 & $6 \cdot 50$ & $0 \cdot 053$ \\
\hline
\end{tabular}

FFA, free fatty acids.

* For details of diets, see Table 1.

$\dagger$ Adjusted for differences in start value $(t=0)$.

Table 5. Statistical differences in total areas below the curves of the various postprandial variables of volunteers consuming test meals varying in carbohydrate:fat and polysaccharide: mono- and disaccharide ratios*

\begin{tabular}{lcccc}
\hline Meal type* & LF/HP & HF/LMD & LF/HMD & HF/LP \\
\hline Glucose & $\mathrm{a}, \mathrm{b}$ & $\mathrm{a}, \mathrm{c}, \mathrm{d}$ & $\mathrm{c}, \mathrm{e}$ & $\mathrm{b}, \mathrm{d}, \mathrm{e}$ \\
Insulin & $\mathrm{f}, \mathrm{g}$ & $\mathrm{f}, \mathrm{h}$ & $\mathrm{h}, \mathrm{i}$ & $\mathrm{g}, \mathrm{i}$ \\
Total glycerol & $\mathrm{j}, \mathrm{k}, \mathrm{l}$ & $\mathrm{j}, \mathrm{m}$ & $\mathrm{k}, \mathrm{m}, \mathrm{n}$ & $\mathrm{l}, \mathrm{n}$ \\
Free glycerol & $\mathrm{o}, \mathrm{p}$ & $\mathrm{o}, \mathrm{q}$ & $\mathrm{q}, \mathrm{r}$ & $\mathrm{p}, \mathrm{r}$ \\
Free fatty acids & $\mathrm{s}, \mathrm{t}$ & $\mathrm{s}, \mathrm{u}$ & $\mathrm{u}, \mathrm{v}$ & $\mathrm{t}, \mathrm{v}$ \\
Total cholesterol Adj. $\dagger$ & $\mathrm{w}, \mathrm{x}, \mathrm{y}$ & $\mathrm{w}, \mathrm{z}$ & $\mathrm{x}, \mathrm{A}$ & $\mathrm{y}, \mathrm{z}, \mathrm{A}$ \\
Free cholesterol Adj. & $\mathrm{B}, \mathrm{C}$ & $\mathrm{B}, \mathrm{D}, \mathrm{E}$ & $\mathrm{D}, \mathrm{F}$ & $\mathrm{C}, \mathrm{E}, \mathrm{F}$ \\
\hline
\end{tabular}

Meals indicated by the same letter are different at the $P$ level indicated below:

a, b, e, f, g, i, j, l, m, n, s, t, u, v, y, C, E, F: $P<001$.

$\mathrm{h}, \mathrm{k}, \mathrm{w}, \mathrm{x}, \mathrm{z}, \mathrm{A}, \mathrm{B}, \mathrm{D}: P<0.05$.

c, d, o, p, q, r: $P<0 \cdot 10$.

* For details of diets, see Table 1.

$\dagger$ Adjusted for differences in start value $(t=0)$.

more or less similar consumption pattern in the periods before the meals. Most of the maximum values of insulin were located in the blood samples taken at $30 \mathrm{~min}$ or $60 \mathrm{~min}$ after the start of the meals, with the highest mean value in the postprandial curves at 30 min. In our previous study (van Amelsvoort et al. 1989), the maximum values of insulin occurred later and the highest mean levels were observed at an average of $60 \mathrm{~min}$ after the start of the consumption. This difference in time may perhaps be explained by the sequence and speed of consumption of meal items: whereas in our previous study the meals were composed of two courses (van Amelsvoort et al. 1989), we used a one-course meal in the present study. Moreover, the majority of the volunteers had already finished eating after approximately $15 \mathrm{~min}$. Hence the induction of insulin secretion by a postprandial increase in the level of blood glucose may well have occurred earlier. 


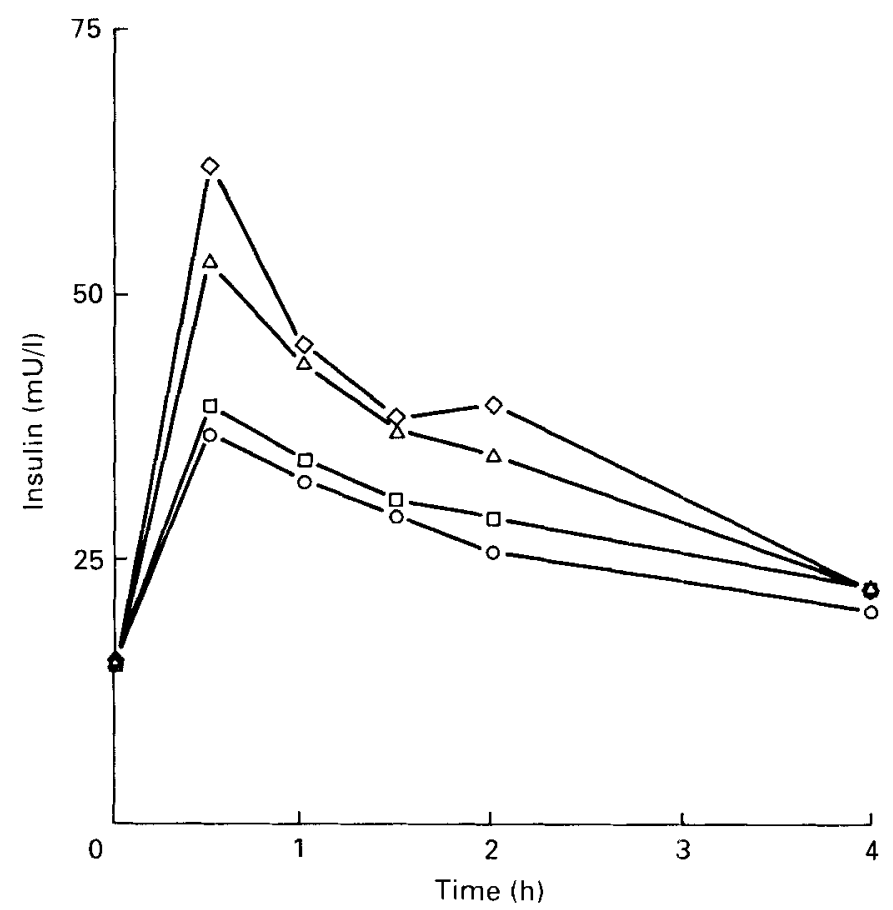

Fig. 2. Mean concentrations of insulin in blood serum from male volunteers $(n 30)$ at various time-points after the start of the consumption of meals containing either $57 \%$ of energy (en $\% ; \mathrm{LF} / \mathrm{HP}, \mathrm{LF} / \mathrm{HMD}$ ) or $37 \mathrm{en} \%$ (HF/LMD, HF/LP) as carbohydrate, and a polysaccharide:mono + disaccharide ratio of $5 \cdot 3$ (LF/HP, $\diamond), 3 \cdot 1$ (HF/LMD, $\square), 0.97(\mathrm{LF} / \mathrm{HMD}, \triangle$ ) or 0.95 (HF/LP, O). For details of diets, see Table 1.

A higher postprandial insulin peak $(P<0.01)$ was observed after the meals containing a larger amount of carbohydrate (meals LF/HP and LF/HMD) than after those containing less carbohydrate (meals HF/LMD and HF/LP). This is in line with our previous finding of a linear relationship between the carbohydrate content of the meal and the average insulin concentration near the top of the postprandial peak (van Amelsvoort et al. 1989). As with the glucose curves (Fig. 1), a small second insulin peak was observed after meal LF/HP. No second peak was seen after meals HF/LMD, LF/HMD or HF/LP. The difference in the type of carbohydrate in the meals was reflected only to a very limited extent in the postprandial curves: slightly lower insulin levels were seen after the meals containing a relatively larger amount of (mono + di)saccharides, i.e. after meal LF/HMD as compared with meal LF/HP, or after meal HF/LP as compared with meal HF/LMD. Assuming that the rate of insulin breakdown was similar after all four meals, the areas below the insulin curves may be regarded as giving a good impression of the amount of insulin secreted by the pancreas. The values given in Tables 4 and 5 show that significantly larger areas were obtained after the carbohydrate-rich meals LF/HP and LF/HMD.

The postprandial curves of total and free glycerol in the blood samples are represented in Figs 3 and 4 respectively. Since free glycerol is only approximately $5 \%$ of the total glycerol content of the blood, the total glycerol value may be regarded as being a good estimate of the triacylglycerol content of the blood. The total glycerol curves (Fig. 3) showed a rapid rise after the consumption of the meals. After the meal containing a low amount of fat and a large amount of simple sugars (meal LF/HMD) the curve levelled off $1 \mathrm{~h}$ after the start of the meal and remained at a nearly constant average level of approximately $1.5 \mathrm{~mm}$. Since no blood samples were collected at later times, we have no 


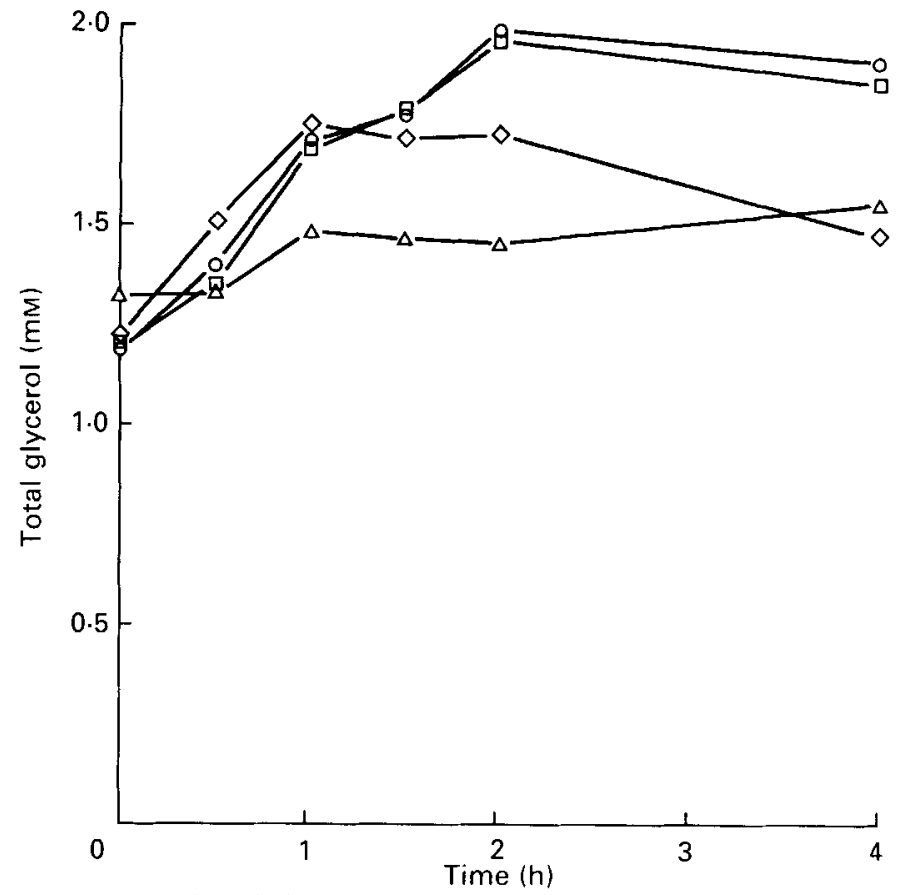

Fig. 3. Mean concentration of total glycerol in blood serum from male volunteers $(n 30)$ at various time-points after the start of the consumption of meals containing either $57 \%$ of energy (en $\% ; \mathrm{LF} / \mathrm{HP}$, LF/HMD) or 37 en $\%$ (HF/LMD, HF/LP) as carbohydrate, and a polysaccharide : mono + disaccharide ratio of 5-3 (LF/HP, $\odot)$, 3.1 (HF/LMD, $\square), 0.97(\mathrm{LF} / \mathrm{HMD}, \triangle)$ or $0.95(\mathrm{HF} / \mathrm{LP}, \mathrm{O})$. For details of diets, see Table 1.

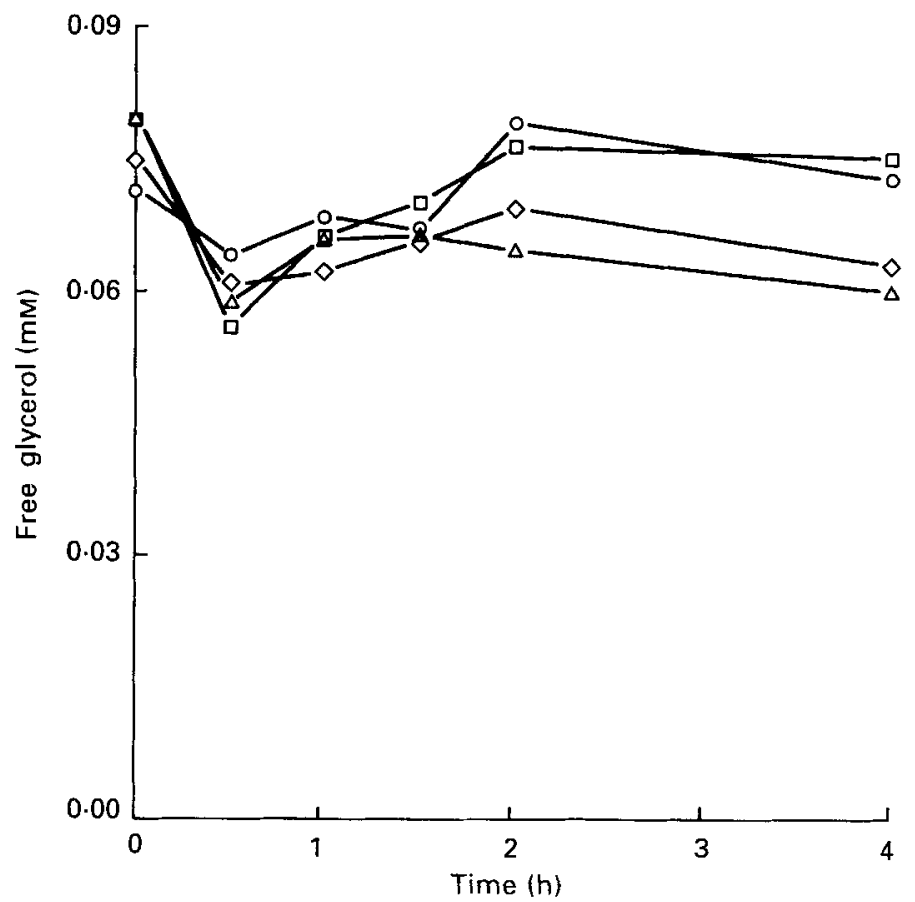

Fig. 4. Mean concentrations of free glycerol in blood serum from male volunteers $(n 30)$ at various time-points after the start of the consumption of meals containing either $57 \%$ of energy (en $\%$; LF $/ \mathrm{HP}, \mathrm{LF} / \mathrm{HMD}$ ) or 37 en $\%$ (HF/LMD, HF/LP) as carbohydrate, and a polysaccharide : mono + disaccharide ratio of $5 \cdot 3(\mathrm{LF} / \mathrm{HP}, \diamond)$, 3.1 (HF/LMD, $\square$ ), 0.97 (LF/HMD, $\triangle$ ) or 0.95 (HF/LP, O). For details of diets, see Table 1. 


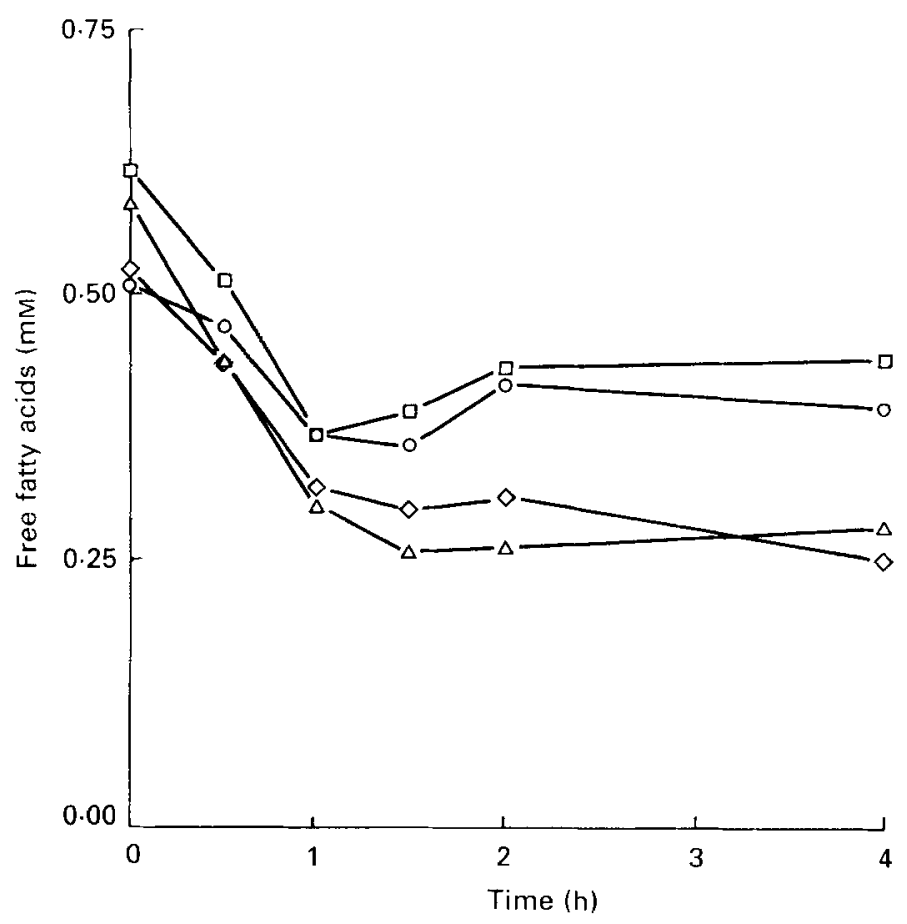

Fig. 5. Mean concentrations of free fatty acios in blood serum from male volunteers ( $n$ 30) at various time-points after the start of the consumption of meals containing either $57 \%$ of energy (en $\% ;$ LF/HP, LF/HMD) or 37 en $\%$ (HF/LMD, HF/LP) as carbohydrate, and a polysaccharide:mono + disaccharide ratio of 5.3 (LF/HP, $\diamond)$, 3-1 (HF/LMD, $\square), 0.97$ (LF/HMD, $\triangle$ ) or 0.95 (HF/LP, O). For details of diets, see Table 1.

indication of exactly when the decrease started. In contrast, meal LF/HP, which contained a similar total amount of carbohydrate but more of the complex type, induced a triacylglycerol level which rose rapidly to a maximum of $1.75 \mathrm{~mm}$, which is significantly higher $(P<0.05)$ than the level at this time after meal LF/HMD. Subsequently, there was a decrease which appeared to result in a final level below that of meal LF/HMD later than $4 \mathrm{~h}$ after the meal. This finding was quite unexpected in view of the fact that simple sugars are generally regarded as being rather effective in inducing hypertriglyceridaemia. The postprandial curves after the fat-rich meals HF/LMD and HF/LP showed a continuous rise up to a maximum of around $2 \mathrm{~mm} 2 \mathrm{~h}$ after the meal, which is significantly higher $(P<0 \cdot 05)$ than the levels at $2 \mathrm{~h}$ after meals LF/HP or LF/HMD.

The postprandial curves of free glycerol in the blood (Fig. 4) all showed a small and rapid drop after the start of the consumption of the meals, which may be explained by an inhibition of the basal lipolytic activity in the body at the start of the consumption of the meal. After about $30 \mathrm{~min}$, the free glycerol rose again after meals HF/LMD and HF/LP (fat-rich) and somewhat less after meal LF/HP. The areas below the curve of both total glycerol and free glycerol, given in Tables 4 and 5 , indicate that larger areas were obtained for these variables after the fat-rich meals HF/LMD and HF/LP.

As with the curves of free glycerol (Fig. 4), the postprandial curves of free fatty acids in the blood all showed a rapid drop after the start of the consumption of the meals (Fig. 5). This may be explained by an inhibition of basal lipolytic activity in the body at the start of the consumption of the meals or an increase in the rate of de novo fat synthesis from free fatty acids induced by the high level of glucose in the blood, or both (see Fig. 1). After 


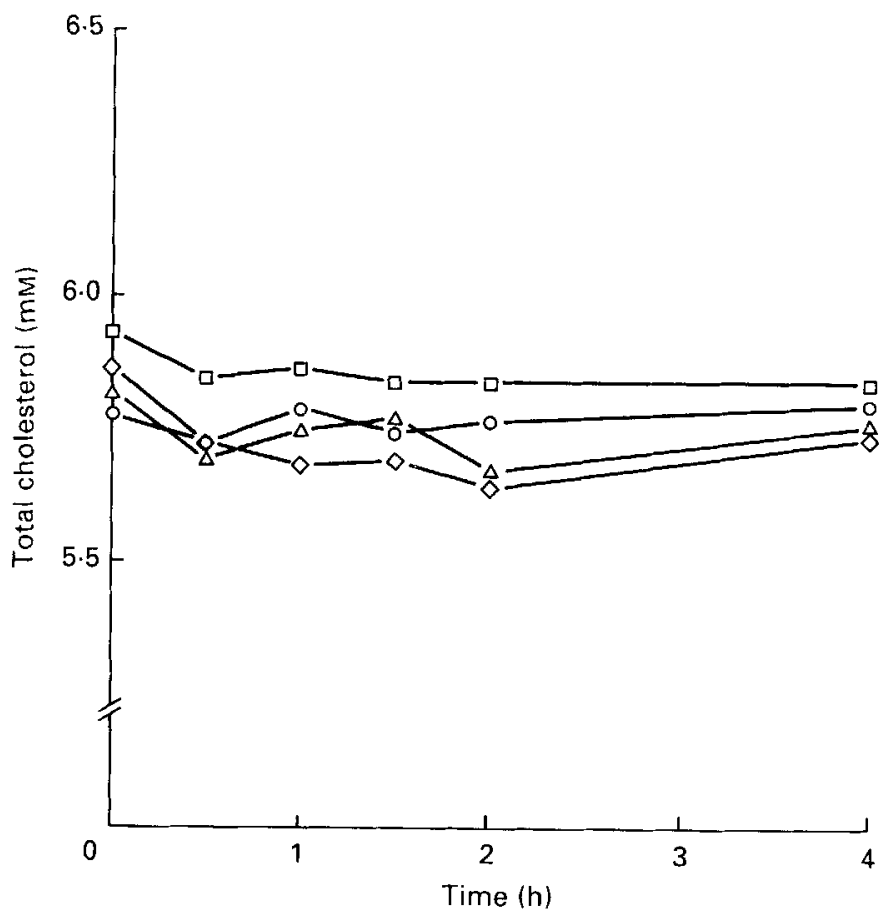

Fig. 6. Mean concentration of total cholesterol in blood serum from male volunteers ( $n$ 30) at various time-points after the start of the consumption of meals containing either $57 \%$ of energy (en $\% ; \mathrm{LF} / \mathrm{HP}, \mathrm{LF} / \mathrm{HMD}$ ) or $37 \mathrm{en} \%$ (HF/LMD, HF/LP) as carbohydrate, and a polysaccharide: mono + disaccharide ratio of $5 \cdot 3$ (LF/HP, $\diamond), 3.1(\mathrm{HF} / \mathrm{LMD}, \square), 0.97(\mathrm{LF} / \mathrm{HMD}, \triangle$ ) or $0.95(\mathrm{HF} / \mathrm{LP}, \mathrm{O})$. For details of diets, see Table 1.

$90 \mathrm{~min}$ the free fatty acid concentration rose again after the fat-rich meals HF/LMD and $\mathrm{HF} / \mathrm{LP}$, but remained more or less constant after the carbohydrate-rich meals LF/HP and LF/HMD. The areas below the curve of free fatty acids were larger $(P<0.01)$ after the fatrich meals than those after the carbohydrate-rich meals (Tables 4 and 5).

The postprandial curves of total cholesterol in the sera displayed significant mealinduced effects (Fig. 6), i.e. the mean values at $1,1 \cdot 5,2$ and $4 \mathrm{~h}$ after the start of meal LF/HP were significantly lower $(P<0.05)$ than those after meal HF/LP. In addition, the areas below the postprandial curves were larger $(P<0.05)$ after the fat-rich meal $\mathrm{HF} / \mathrm{LP}$ than those after the carbohydrate-rich meals LF/HP and LF/HMP, or after meal HF/LMD compared with meal LF/HP (Tables 4 and 5). These differences, however, were rather small and may have been caused by the differences in cholesterol content of the four meals (see Table 1). The slight drop in cholesterol concentration at the start of the curves (also seen for free cholesterol except for meal type HF/LP; see Fig. 7) may have been due to a reduction in the physical activity of the volunteers at the start of the meal which has been shown to affect the concentration of blood cholesterol (Statland et al. 1976). In view of the fact that diet-induced effects on blood cholesterol (such as that induced by the polyunsaturated:saturated fatty acid ratio) may in general be assumed to require a much longer time interval, these results were in line with our expectations. The postprandial curves of free (unesterified) cholesterol in the sera were scattered and did not appear to display significant meal-induced effects (Fig. 7). However, the calculated areas below the curves (Tables 4 and 5) were larger $(P<0.05)$ after meals HF/LMD and HF/LP which contained a larger amount of cholesterol than after meals LF/HP and LF/HMD (see Table 1). 


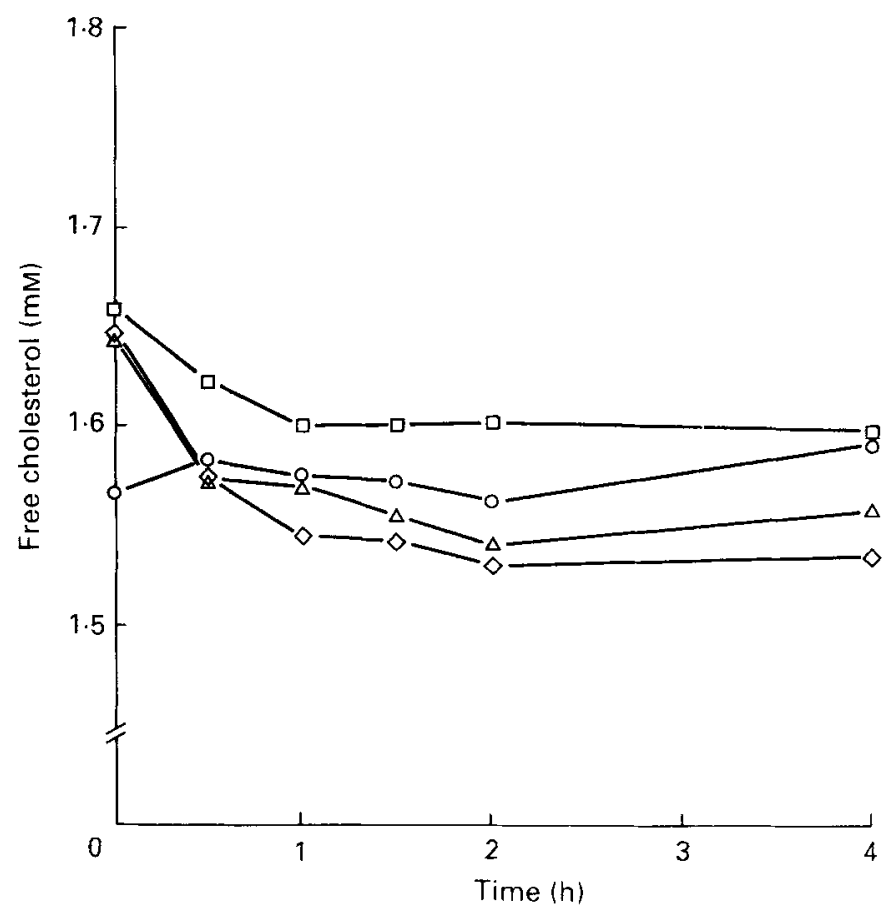

Fig. 7. Mean concentrations of free cholesterol in blood serum from male volunteers ( $n$ 30) at various time-points after the start of the consumption of meals containing either $57 \%$ of energy (en $\%$ LF $/ \mathrm{HP}, \mathrm{LF} / \mathrm{HMD}$ ) or 37 en $\%$ (HF/LMD, HF/LP) as carbohydrate, and a polysaccharide:mono + disaccharide ratio of $5 \cdot 3$ (LF/HP, $\diamond), 3 \cdot 1$ (HF/LMD, $\square$ ), 0.97 (LF/HMD, $\triangle$ ) or 0.95 (HF/LP, O). For details of diets, see Table I.

\section{DISCUSSION}

At the start of our meal-eating studies in volunteers it was established that in order to obtain the best approximation of the day-to-day practice in the consumption of meals, the energy contents of the test meals should be adjusted to the habitual intake of each individual. In a previous study (van Amelsvoort et al. 1989) we had tried to achieve this by serving the volunteers at noon a meal which was made equal to $40 \%$ of the average daily energy intake of each individual. However, this approach appeared to be rather unsatisfactory: the volunteers often had problems in consuming the full meal. Therefore in the present study, before the start of the actual experiment, the volunteers were offered a meal composed of equal proportions of meal types LF/HP, HF/LMD, LF/HMD and $\mathrm{HF} / \mathrm{LP}$ which they could eat ad lib. Since the introductory meal was served at the same hour of the day on which the actual experiment was going to take place, this approach was thought to give the best estimate of the amount of food that an individual volunteer could generally consume at that time of day. However, due to the palatability of this mixed meal type, the volunteers unexpectedly consumed rather large quantitities of it. Since we used a mixture of the high-fat meal types together with the high-carbohydrate meal ones, it was expected that the volunteers would again have problems in coping with the larger volume of the high-carbohydrate meals in the actual experiment. Therefore the sizes of the meals given in the experiment were adjusted downwards. Analysis of the postprandial curves after the experiment revealed that there was no significant correlation between the size of the test 
meal or the percentage of total energy intake in the test meal and the postprandial area below the curve or the 30 min value or the maximum postprandial value of glucose, insulin or total glycerol. Only for insulin after the (mono + di)saccharide-rich meal LF/HMD was a weak correlation detected between meal size and the postprandial area under the curve, and also between the percentage of total energy intake in the test meal and the postprandial area below the curve or the $30 \mathrm{~min}$ value or the maximum postprandial value. Since the inter-individual variation could have precluded detection, the absence of a systematic correlation in most of the cases does not prove that there is no effect of a (limited) variation in meal size on postprandial variables. However, preliminary findings obtained in a related study on the effects of a limited variation in meal size indicated that the changes in postprandial variables are relatively small compared with those induced by the changes in meal composition, and in general they will not affect the conclusions obtained in a comparative meal-eating study (J. M. M. van Amelsvoort, P. van Stratum, G. P. Dubbelman and R. N. Lussenburg, unpublished results).

The blood glucose curves (Fig. 1) showed a postprandial peak at $30 \mathrm{~min}$, and a second but smaller peak $2 \mathrm{~h}$ after consuming meals LF/HP and HF/LMD, but not after meals LF/HMD and HF/LP. The appearance of this second peak might be related to the relative amounts of slowly digested complex carbohydrates in the meals. Indeed, the highest $P$ : MD ratios were present in meals $\mathrm{LF} / \mathrm{HP}$ and $\mathrm{HF} / \mathrm{LMD}$ (5.3 and 3.1 respectively) compared with 0.97 and 0.95 in meals LF/HMD and HF/LP respectively. Although the areas below the glucose curves increased with increasing carbohydrate content, they were independent of the type of carbohydrate in the meals (Tables 4 and 5). Similar observations were made for the areas below the postprandial insulin curves. This indicates that the advice by health councils to increase the consumption of complex carbohydrates may be oversimplified, and needs to be amended in order to be more specific with respect to the (rate of) digestion of the complex carbohydrates.

The insulin secretion tended to be slightly larger after the meals containing a relatively larger amount of complex carbohydrates (meal types LF/HP and HF/LMD) compared with those containing relatively higher amounts of (mono + di)saccharides (meal types LF/HMD and HF/LP). It has been suggested that complex carbohydrates may be degraded and taken up more slowly than simple carbohydrates. However, this does not necessarily imply that a slow rate of digestion of complex carbohydrate is indeed the explanation of the observed second glucose peak (Fig. 1): since the major part of the complex carbohydrate is present mainly in a particular entity of the meal i.e. the grains of rice, physical factors such as the envelopment of the carbohydrate could very well play an important (additional) role.

The rapid drop in the postprandial curves of free glycerol and free fatty acids in the blood after the start of the consumption of the meals may be due to an inhibition of the basal lipolytic activity in the body (by the rise in insulin level, see Fig. 2). After $1 \mathrm{~h}$ the levels of both free glycerol and free fatty acids rose again after the fat-rich meals, but after the carbohydrate-rich meals free glycerol rose less and free fatty acids not at all. This rise is apparently due to the release of free glycerol and free fatty acids by the action of lipoprotein lipase (EC 3.1.1.34) on the triacylglycerols in the chylomicrons. After the carbohydraterich meals, however, the free fatty acid level remained low, which is apparently due to inhibited lipolysis and to an increase in the rate of de novo synthesis of triacylglycerol from free fatty acids. This synthesis is stimulated by both the high level of glucose (which is converted into glycerophosphate), and the concomitantly high level of insulin in the blood.

All four meals produced an increase in the triacylglycerol level of the blood. Elevated triacylglycerol levels in the blood have been related to an increased risk of atherosclerosis. Since the size of the risk may be dependent on the type of lipoprotein in which the 
triacylglycerols are incorporated, this conclusion may be an oversimplification. Therefore, the potential health risk of an increase in the blood insulin content induced by carbohydrate-rich meals may at least partially be balanced by a decrease in the risk due to the lowering of the average blood triacylglycerol content after consumption of this mealtype.

After the simple sugar-rich meal LF/HMD the total glycerol curve levelled off $1 \mathrm{~h}$ after the start of the meal. Subsequently, it remained at a nearly constant average level of approximately $1.5 \mathrm{mM}$. Meal LF/HP, which contained a similar total amount of carbohydrate but more of the complex type, induced a triacylglycerol level which rose to a higher maximum of $1.75 \mathrm{~mm}$. The finding of a lower maximum value after meal LF/HMD appears to be in conflict with the general belief that simple sugars are particularly effective in inducing hypertriglyceridaemia. However it is possible that the triacylglycerol level after meal LF/HMD sustained its slow rise for many hours after the last measuring point at $4 \mathrm{~h}$. Therefore, this finding will have to be confirmed by an experiment in which the collection of blood samples is extended in time before definite conclusions can be drawn.

The authors thank the volunteers for their participation in the study, Professors J. G. A. J. Hautvast, J. H. Koeman and H. K. A. Visser for ethical supervision, Miss M. B. van Doorn for medical screening of the volunteers, Mrs W. M. C. Dubelaar for collecting the dietary histories, the calculation of the recipes and the preparation of the meals, Mr. J. Zaalberg for statistical analysis, Messrs C. G. Blonk and A. van der Beek for collecting the blood samples, and Messrs P. Moret, J. J. Stam and W. G. L. van Nielen and Miss E. M. C. ter Horst for the processing of the blood samples and the various analyses.

\section{REFERENCES}

Commissie UCV (1984). Uitgebreide Voedingsmiddelentahel 1984, 's-Gravenhage: Voorlichtingsbureau voor de Voeding.

Crapo, P. A. (1986). Carbohydrate in the diabetic diet. Journal of the American College of Nutrition 5, $31-43$.

Flodin, N. W. (1986). Atherosclerosis: an insulin-dependent disease? Journal of the American College of Nutrition 5. $417-427$.

Heraud, G. (1985). Glucides simples glucides complexes. Médecine et Nutrition 21, 247-256.

Jenkins, D. J. A., Wolever, Th. M. S., Jenkins, A. L., Giordano, C., Giudici, S., Thompson, L. U., Kalmusky, J., Josse, R. G. \& Wong, G. S. (1986). Low glycemic response to traditionally processed wheat and rye products: bulgur and pumpernickel bread. American Journal of Clinical Nutrition 43, 516-520.

Jenkins, D. J. A., Wolever, Th. M. S., Jenkins, A. L., Josse, R. G. \& Wong, G. S. (1984a), The glycaemic responsc to carbohydrate foods. Lancet ii, 388-391.

Jenkins, D. J. A., Wolever, Th. M. S., Jenkins, A. L., Thorne, M. J., Lee, R., Kalmusky, J., Reichert, R. \& Wong, G. S. (1983). The glycaemic index of foods tested in diabetic patients: a new basis for carbohydrate exchange favouring the use of legumes. Diabetologia 24, 257-264.

Jenkins, D. J. A., Wolever, Th.M.S., Wong, G. S., Patten, R., Hall, M., Bird, J., Josse, R. G., Jepson, E. M. \& Little, J. A. (1984b). Glycemic index of foods: controlling the rate of nutrient absorption in the management of diabetes and hyperlipidemia. In Diet, Diabetes and Atherosclerosis, pp. 227-239 [G. Pozza, P. Micossi, A. L. Catapano and R. Paoletti, editors]. New York: Raven Press.

Lee, P. C., Brooks, S. P., Kim, O., Heitlinger, L. A. \& Lebenthal, E. (1985). Digestibility of native and modified starches: in vitro studies with human and rabbit pancreatic amylases and in vivo studies in rabbits. Journal of Nutrition 115, 93-103.

Marr. J. W. (1971). Individual dietary surveys, purposes and methods. World Review of Nutrition and Dietelics 13, 105-164.

Statland, B. E. \& Winkel, P. (1976). Variations of cholesterol and total lipid concentrations in sera of healthy young men. Differentiating analytic error from biological variability. American Journal of Clinical Pathology 66 , 935943.

Stout, R. W. (1985). Overview of the association between insulin and atherosclerosis. Metaholism 34, Suppl. 1, $7-12$.

Thorburn, A. W., Brand, J. C. \& Truswell, A. S. (1986). The glycaemic index of foods. Medical Journal of Australia 144, 580-582. 
Thorburn, A. W., Brand, J. C. \& Truswell, A. S. (1987). Slowly digested and absorbed carbohydrate in traditional bushfoods: a protective factor against diabetes? American Journal of Clinical Nutrition 45, 98-106.

Torsdottir, I., Alpsten, M., Andersson, D., Brummer, R. J. M. \& Andersson, H. (1984). Effect of different starchy foods in composite meals on gastric emptying rate and glucose metabolism. I. Comparisons between potatoes, rice and white beans. Human Nutrition: Clinical Nutrition 38C, 329-338.

Van Amelsvoort, J. M. M., Van Stratum, P., Kraal, J. H., Lussenburg, R. N. \& Houtsmuller U. M. T. (1989). Effects of varying the carbohydrate : fat ratio in a hot lunch on postprandial variables in male volunteers. British Journal of Nutrition 61, 267-283.

Wolever, Th. M. S. \& Jenkins, D. J. A. (1986). The use of the glycemic index in predicting the blood glucose response to mixed meals. American Journal of Clinical Nutrition 43, $167-172$.

Zilversmit, D. B. (1979). Atherosclerosis: a postprandial phenomenon. Circulation 60, 473-485.

Zilversmit, D. B. (1984). Postprandial hyperlipidemia and its relation to atherosclerosis. In Latent Dyslipoproteinemia and Atherosclerosis, pp. I-8 [J. L. de Gennes, J. Polonovski and R. Paoletti, editors]. New York: Raven Press. 